www.jmscr.igmpublication.org

Index Copernicus Value: 79.54

ISSN (e)-2347-176x ISSN (p) 2455-0450

crossrefDOI: https://dx.doi.org/10.18535/jmscr/v7i2.58

\title{
Sturge-Weber syndrome: A Case Report in estimating diagnostic importance of Neuroimaging
}

\author{
Authors \\ Dr Abhishek Kaushik ${ }^{1}$, Dr Sachin ${ }^{2}$, Dr Kirti Chaturvedy ${ }^{3}$, Dr Prateek Sihag ${ }^{4}$ \\ ${ }^{1,2}$ PG MD Resident Doctor, ${ }^{2}$ Prof., ${ }^{3}$ Assistant Prof. \\ Dr SNMC Jodhpur Rajasthan, India
}

\begin{abstract}
Sturge Weber syndrome (SWS) is a rare neurocutaneous syndrome, that is sporadic and in majority of the cases is characterized by a port wine stain. We aimed to present a SWS patient with the history of convulsions and to draw attention towards the role of MRI and NCCT in evaluating the cases of SWS. A 6year-old male patient presented our department for NCCT head with complaints of an episode of convulsion. At his physical examination a facial nevus was observed. He had a history of convulsions at the age of 8 months.
\end{abstract}

\section{Introduction}

Sturge-Weber syndrome is also known as encephalo-trigeminal angiomatosis. Its characteristic features are:-

1) A capillary malformation of the skin (portwine-angioma) generally in the distribution of the trigeminal nerve,

2) Retinal choroidal angioma (either with or without glaucoma), and

3) A cerebral capillary-venous leptomeningeal angioma $^{(1)}$.

Convulsions will develop in 75 to $80 \%$ of average patients with SWS; up to $93 \%$ of those who have bilateral cerebral involvement will develop epilepsy ${ }^{(2,3)}$. A questionnaire survey of patients in the Sturge-Weber Foundation (SWF) registry discovered that seizures will manifest in the first year of life in about $75 \%$ of those who develop epilepsy $^{(4)}$. Typical seizures are partial (either simple or complex partial), but infantile spasms and myoclonic seizures can occur ${ }^{(2)}$.

\section{Case Report}

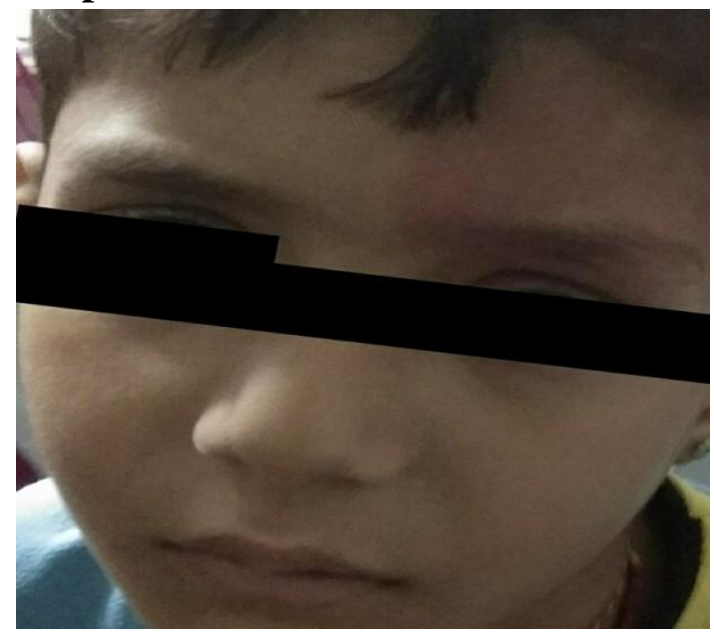

6-year-old male patient has Chief complaint of headache for 3 days one episode of convulsion one day back and reddish discoloration on the left side of the face. 
History revealed that the reddish discoloration (port wine stain) was present on the face since birth and was gradually darkening with age.

Family history was noncontributory. There was no visible sign of mental retardation and patient had positive past history of convulsions also when he was 6 months old.

NCCT Head Examination- The scan revealed hyperdense lesion noted in left parieto-occipital region arranged as parallel subcortical calcification (tram-track appearances)
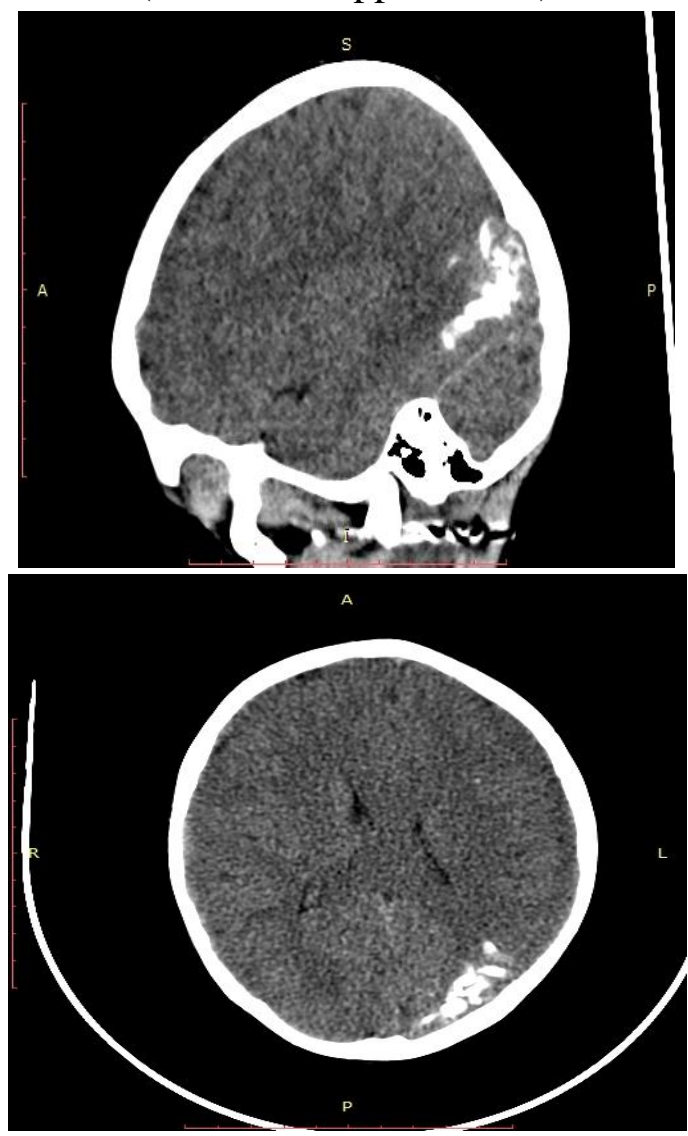

Ultrasound Abdomen Examination: No abnormality was detected.

Chest X-Ray Findings-No abnormality was detected.

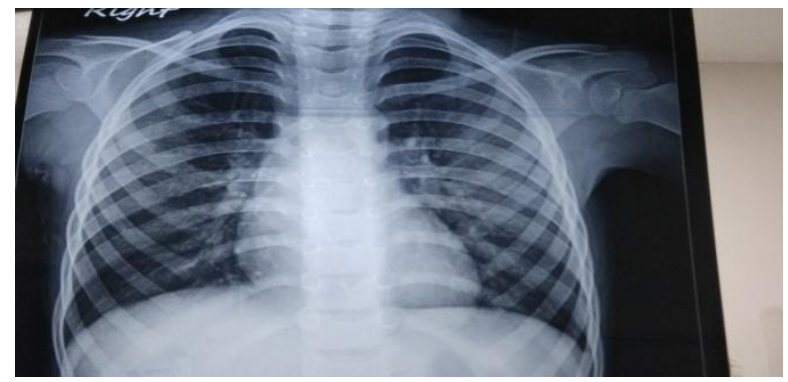

MRI Findings

For the confirmation of diagnosis contrast enhanced MRI Brain study was performed. The study revealed intense serpentine leptomeningeal enhancement representing pial angiomatosis of subarachnoid space in the left occipital, parietal lobes with engorged enhancing ipsilateral choroid plexus; findings in keeping with Sturge Weber syndrome. There is accelerated myelin maturation of the involved left occipital and parietal lobes with prominent $\mathrm{T} 2 \mathrm{~W}$ hypo intensity. Rest of brain parenchyma appears normal.

\section{Discussion}

Facial angioma represent hamartomatous capillary malformations and are named so due to the deep red hue that they leave on the skin or mucosa. Such lesions can bleed profusely when accidentally traumatized.

MRI findings in the patients of Sturge Weber syndrome may include-

- Pial angiomata in the parieto-occipital region

- Cortical calcifications subjacent to the cortex and white matter, typically in the parietooccipital area

- Prominent choroid plexus;

- Atrophy of the ipsilateral cerebral hemisphere (on the side of angioma)

- Enlarged and elongated globe of the eye ${ }^{(5)}$

Differential diagnosis can include Rendu-OslarWeber syndrome, angio-osteodystrophy syndrome, Maffuci's syndrome, Von Hippel Lindau disease, and Klippel Trenaumy-Weber syndrome. However, in most cases definitive diagnosis can be made by careful clinical examination, proper history, ultrasound examination of abdomen, chest $\mathrm{X}$ ray and other relevant investigations ${ }^{(6)}$.

\section{Treatment}

Treatment and prognosis depend upon the nature and severity of clinical features. Presence of facial angioma can cause deep psychological distress to patient and development of personality is affected in most patients. 
Seizures in SWS can usually be controlled by the available antiepileptic medication. (ex carbamazepine). In cases of drug resistant epilepsy, lobectomy and Hemispherectomy are possible treatment options in infants ${ }^{(5)}$.

\section{Conclusion}

This is a case of SWS, diagnosed early with proper neuroimaging techniques (CT and MRI) and the case is receiving apt treatment and is showing normal neurodevelopment and is having normal academic performance at school.

Consent- All authors declare that 'written informed consent was obtained from the mother of patient for publication of this case report and accompanying images.

Ethical Approval- This study is not animal experiments or experimental study. This is a case report.

Conflict of interest- No conflict of interest was declared by the authors.

\section{References}

1. Osborn's brain imaging, pathology and anatomy, first edition, page 2666-2670.

2. Bebin EM, Gomez MR. Prognosis in Sturge-Weber disease: comparison of unihemispheric and bihemispheric involvement J Child Neurol. 1988;3:181-184.

3. Oakes WJ. The natural history of patients with the Sturge-Weber syndrome. Pediatr Neurosurg. 1992; 18:287-90.

4. Sujansky E, Conradi S. Sturge-Weber syndrome: age of onset of seizures and glaucoma and the prognosis for affected children. J Child Neurol. 1995; 10:49-58.

5. Grainger and Allison's diagnostic radiology, a textbook of medical imaging, $6^{\text {th }}$ edition, page 1553 .

6. Textbook of Radiology and imaging, David Sutton, $7^{\text {th }}$ edition, page 1563. 